\title{
Stakeholders' Resistance in Single Building Renewal: Bagdat Avenue, Istanbul
}

\author{
Ilkim Markoc \\ Faculty of Architecture, Yildiz Technical University, PO box 34349, Istanbul, Turkey
}

\begin{abstract}
Bagdat Avenue is a major pedestrian-shopping axis of Istanbul Asian Side, and also a residential area with a unique culture shaped by the long-term residents thereof. Law on Transformation of Areas under Disaster Risk (no:6306) enacted in 2012, triggered intense plot-based transformation activities in Bagdat Avenue, where transformation decisions are taken by the majority of votes of property owners on a plot basis. The purpose of this study is to determine, in the context of themes and codes, the motivation underlying the strong-willed attitude of residents who refuse renewal of their building despite appealing economic advantages. First, literature was reviewed to determine user's expectations of plot-based urban transformation, followed by an in-depth interview made with 19 property owners living in Kuzu Street of Saskinbakkal, Bagdat Avenue, who refused transformation. In conclusion, "sense of belonging, housing satisfaction and issue of trust" codes were defined regarding motivations of stakeholders who refused urban transformation.
\end{abstract}

Keywords: Single Building Renewal, Stakeholders, Bagdat Avenue, Istanbul

DOI: $10.7176 /$ RHSS/10-6-07

Publication date:March $31^{\text {st }} 2020$

\section{Introduction}

Neoliberal policies those gathered momentum with the re-birth in the 20th century of laissez-faire[1] economic system is today in the form of tools that create an investment value and yield economic advantage by reproducing an urban space (Yhau \& Chan, 2008). This process started around the 1950s in Turkey (Kuyucu \& Unsal, 2010). The government that is the sole-ruling party in Turkey since the 2000s has attached priority in the activities of reproducing urban spaces considering the disaster risk (Angell, 2014).

The fact that the 1999 Marmara Earthquake has caused great destruction in the housing stock put a spotlight on the potential earthquake risk for Istanbul. For that very reason, both the academic community and government in power have emphasized the urgency of renewing the existing housing stock. In addition to the statements it made supporting the urban transformation, the government has set the legal frame of the transformation activities by enacting the Law on Transformation of Areas under Disaster Risk (no. 6306) in 2012. However, in time it was revealed that these activities served to the purpose of generating economic advantages by producing more luxurious housings on high income generating urban lands rather than improving the housing stock that is under risk (Koramaz, 2018). Another reason as to why such rapid transformation activities are encouraged, as a government policy is the positive impact such is on national economic indicators and unemployment rate (Balaban, 2012).

The purpose of this study is to analyze and set forth, in the context of themes and codes, the motivation underlying the strong-willed attitude of residents who do not permit renewal of their building despite all the economic advantages they will gain. To begin with, the building transformations on a pilot basis and expectations of users from such is set forth on a conceptual basis. This is followed by in-depth face-to-face interviews made in November-December 2019 with residents in Şaşkınbakkal who refused to allow the transformation of their buildings $(\mathrm{n}=19)$. The snowball sampling method is used, and samples are selected randomly. Interviews were recorded with a tape-recorded and processed according to the content analysis method. The findings in the context of themes and codes and significant statements made by samples have been presented herein directly.

\section{Literature Review}

\subsection{Single Building Renewal}

It is seen that earthquake risk is not the sole motivation underlying the examples of transformation activities both in the area and on building basis being carried out as of 2012 within the scope of Law no. 6306, and that economic and social matters are also relevant in that respect (Lovering \& Turkmen 2011). The change in the social and cultural essence of the districts as the result of large-scale projects is also witnessed in transformation projects on a structured basis. These led to an increase in the value of the property and the land, as well as a radical increase in the functional properties of the area and volume of urbanized land and constructions. These direct changes give rise to further and more deep-seated problems that indirectly have ecological and social dimensions (Kayasu \& Yetiskul, 2014; Ozkan Eren \& Ozcevik, 2015).

In terms of the transformation of buildings initiated with Law No.6306, Risky Building status and being in danger of severe damage or at risk of Risky Building status is determined by submitting to the local governments 
the technical analysis report for the construction quality of the buildings as demanded by beneficiaries. The law requires that risky buildings are demolished within the following two months and re-built within the same plot and according to the scale of the property. During this process, property owners need to choose the contractors; and sign a contract. Upon transformation, the physical quality of the building is improved, accompanied by a rise in the value of the property and rent income.

\subsection{Stakeholder Expectations}

The involvement of multiple stakeholders, the existence of multiple objectives, and the scope of the building to be constructed complicate the process (Williams, 2002). Putting forth the expectations of the stakeholders at the beginning of the entire construction process and managing the process is crucial (Atkinson et al., 2006; Olander \& Ladin, 2005). Urban transformation projects are complex projects with stakeholders comprised of both public and private actors. Expectations of stakeholders in urban transformation projects on an area basis and are generally different than the stakeholders of projects on a building basis. Koskela and Ballard (2006) have demonstrated the importance of the identification process in spelling out the underlying reason behind customer's requirements in a construction project.

Hin and Xin (2011) emphasize that in China, when deciding to support an urban transformation project, the top priority is attached to the economic assessment. Stakeholders expect to gain an economic benefit in these projects; however, the perspectives as to these expectations differ. Developers, builders, and various suppliers are also important stakeholders, and their expectations are profit-oriented, and they aim to pursue economic gain, whereas local governments expect the transformation to contribute to the development of the region (Gruneberg, 2007; Abidin, 2010).

The research carried out in Chongqing by Zhuang et al. in 2017 set forth the expectations of various stakeholders from the transformation process. In this research Economic Benefits to Governments and Local People rank the first in mean differences, and this is followed by the factors on the improvement of the old neighborhood. Because the affected residents in rehabilitation projects do not move out of the old neighborhoods, the rehabilitation of their neighborhoods and dwellings are their core interests (Zhuang, 2017). Another research carried out in Shanghai by He et al. in 2019 revealed that initial expectation in a transformation project is "economic benefits for governments and other stakeholders" (He et al., 2019).

\section{Case Study}

Bagdat Avenue is an essential shopping-pedestrian line of the Asian side of Istanbul. Also, the avenue and its vicinity is one of the most prestigious residential neighborhood of Istanbul with a history going back many years. Saskinbakkal was the summer districts of Istanbul until the Property Ownership Law enacted in 1965 and considered as the legal basis for the construction of multi-storey buildings. As of the end of 1960s, a trend started where low-rise mansions were replaced by multi-storey buildings. 1999 Marmara Earthquake was another essential breakpoint for Saskinbakkal. Law on Transformation of Areas under Disaster Risk" (no.6306) enacted in 2012 constitutes the legal basis of the rapid transformation in this respect. Local government took the lead in making this process more attractive for stakeholders by permitting dense housing. Bagdat Avenue location on Istanbul Asian side is given in Figure 1. In Figure 2, the location of Kuzu Street on Bagdat Avenue is presented. 


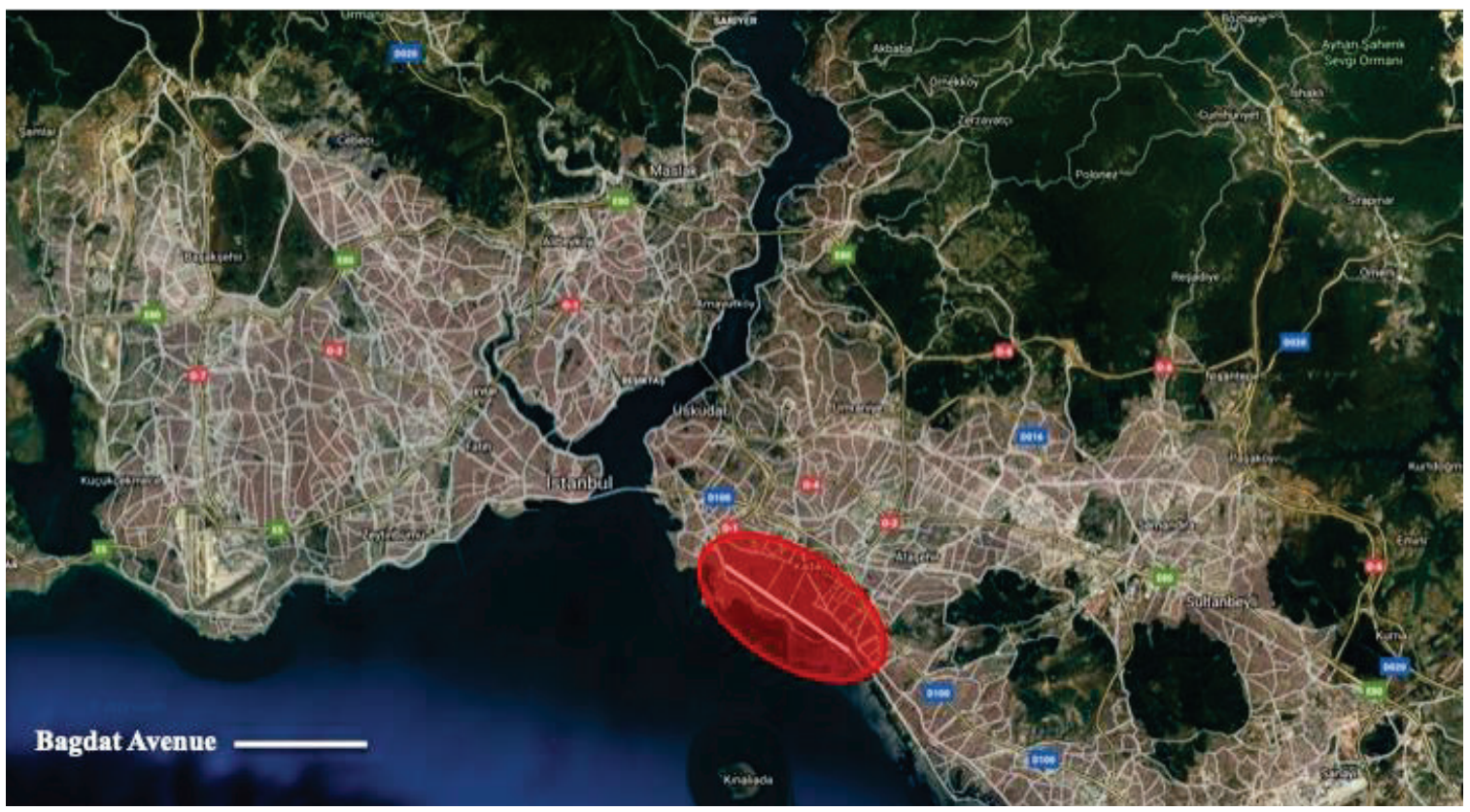

Figure 1. Bagdat Avenue location on Istanbul Asian side.

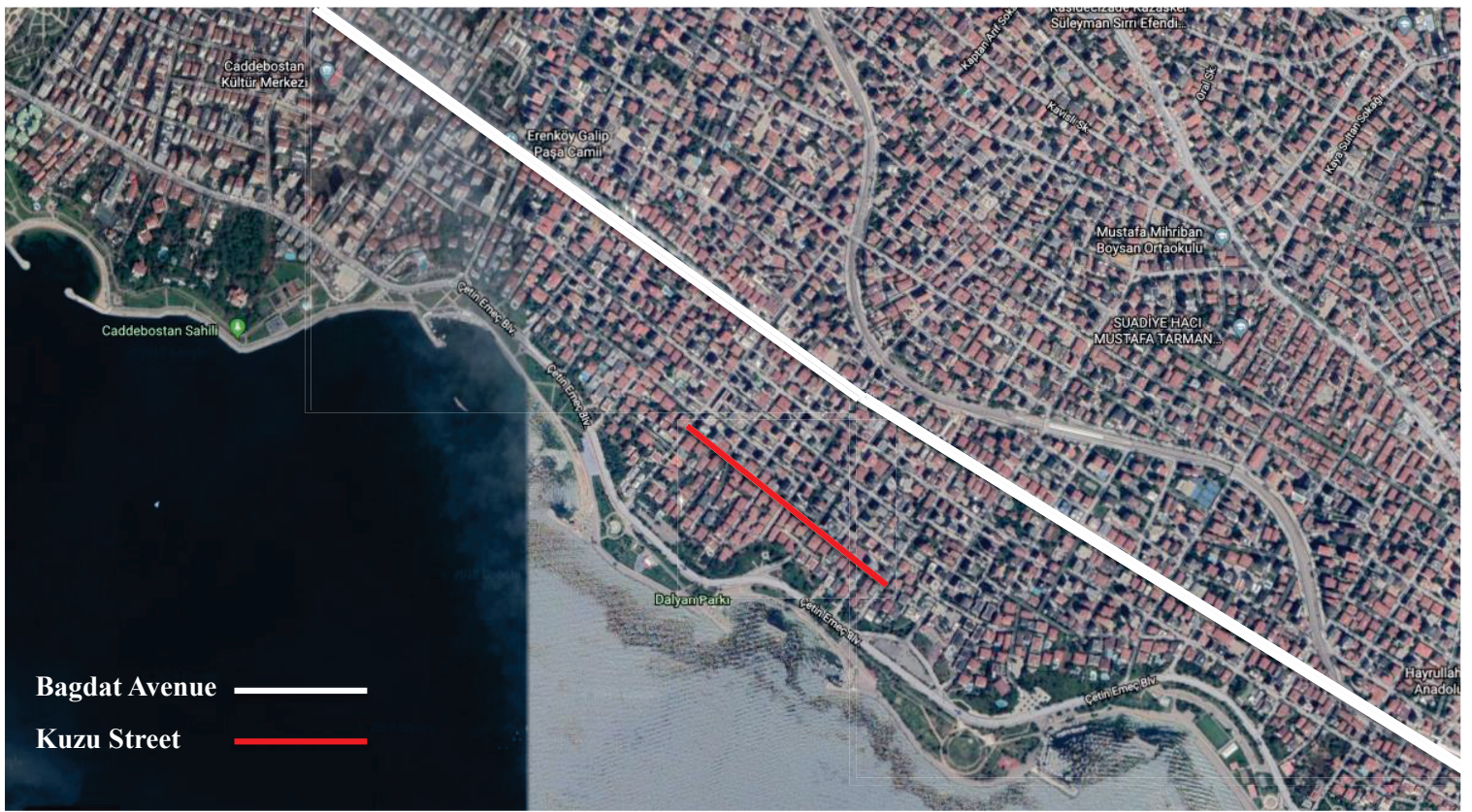

Figure 2. Bagdat Avenue-Kuzu Street

An attractive quality of the Saskinbakkal district is the neighborhood's desirable location between the coastline and Bagdat Avenue, m2 unit price of the houses is around USD 1800, making it one of the districts of Istanbul with the highest property values. This area is undergoing an intense transformation phase as a consequence of a collusive agreement between local government, contractors, and stakeholders, although the disaster risk of the neighborhood is rather low. The motivation underlying the ongoing rapid transformation phase of this area that has started with the claim that the area entails a disaster risk even though the risk is rather low is the fact that all stakeholders achieve an economic benefit from this process (Berkmen \& Turgut, 2019). The number of buildings demolished and rebuilt in Saskinbakkal in the last decade is more than the number of buildings that survived. Most of the residents in the area apply to contractors asking for the renewal of their old buildings that are not potentially earthquake-prone, tempted by the economic advantages they will gain.

\subsection{Method}

To achieve the purpose of the study, in-depth face-to-face interviews ( $\mathrm{n}=19)$ made in November-December 2019, with residents residing in Kuzu Street who refused to allow the transformation of their buildings. The snowball sampling method is used, and samples are selected randomly. In-depth interviews were recorded on tape with the 
permission of interviewees. Based on the content analysis result of the interviews, themes and codes are generated. Significant statements made by samples have been presented herein directly.

3.2. Presentation of Field Data

Themes and codes deducted based on field data are given in Table 1.

Table 1. Themes and Codes

T1 To desire to preserve the sense of belonging towards space.

T2 Lack of trust in contractors

T3 Believing that the house is not earthquake-prone

T4 Believing that there is no need to renew the house

It is not daring to go through the transformation process with the concern that it will be too complicated.

T6 The desire to maintain family inheritance

Reluctance to move into a smaller house as the result of the transformation process

Don't need an increase in the economic value of the house upon transformation.

\begin{tabular}{lcc} 
SENSE & OF & $\mathrm{C} 1$ \\
BELONGING & & C3 \\
ISSUE OF TRUST & & C2 \\
HOUSING & & \\
SATISFACTION & & \\
HOUSING & \\
SATISFACTION & & $\mathrm{C} 2$ \\
ISSUE OF TRUST & & $\mathrm{C} 3$ \\
$\begin{array}{l}\text { SENSE } \\
\text { BELONGING }\end{array}$ & OF & $\mathrm{C} 1$ \\
HOUSING & & \\
SATISFACTION & & $\mathrm{C} 2$ \\
HOUSING & & \\
SATISFACTION & & $\mathrm{C} 2$ \\
\hline
\end{tabular}

T1- To desire to preserve the sense of belonging towards the space

Interviewees explained that they feel both a physical and social sense of belonging to their houses, where they have been living for a long time, and for that reason they don't want to renew their houses, and here are the statements they made in this respect:

We moved here in 1975 right after the apartment was built. This area was a summer district back then. In time the city expanded and our neighborhood has become an inner-city. But it has always been a lovely neighborhood. We are now used to living here. I cannot move to another neighborhood when my house is pulled down. They don't want to change the setting they are accustomed to (A.M.,80).

Everyone in my apartment has been living here for many years. We know everyone who comes in and goes out of the apartment. After the transformation, some of these people may leave or even we may move and don't come back here again because it is tough to move 2 times within 2-3 years. I am happy to live here, in this apartment, with the people I am acquainted with (S.M.,72).

We moved here in 2010. My children were born here. We moved here because we love this neighborhood, the lifestyle, the culture here, and I want my children to grow up here (H.E.,38).

I don't want the house I developed a sense of belonging to go down (B.K.,68).

I have been living in this apartment for 25 years. I think it is the loveliest neighborhood in Istanbul. Indeed, our house is not brand new, but we did some renovations. It is not earthquake-prone either. People opt for transformation projects not because of the earthquake risk, but rather to increase the value of their property. I don't want such a thing. I want to spend my days here when I am old. (M.A.,50).

T2- Lack of trust in contractors

Since the transformation process has been going on for years now, the residents of the neighborhood witnessed some bad experiences where the contractors demolished the houses and vanished without completing the construction, and they fear that they may have to go through a similar experience themselves. Here are their thoughts on this issue:

If we decide to pull down and renew the houses we need to rent and move to another house for 3 years. The contractor pays the rent during that time. But I can't be sure whether he will or not. We heard many stories where the contractor goes bankrupt after he pulls down the houses, and vanishes without completing the construction (H.E.,38).

After this age, I don't want to suffer when the contractor I rely on lets me down (Y.M.,65).

We don't know whether the products, that contractor will use, will be of high quality (C.M.,65)

T3- Believing that the house is not earthquake-prone

Property owners believe that their building is not earthquake-prone, which they consider as the fundamental reason when deciding to go through a transformation process. Their comments were as follows:

Right after the earthquake in 1999, everyone started to apply for a technical analysis of their building. We did too and the result was that our building is earthquake-resistant. Technical experts told us that our building was robust 
but that we may renew it if we wish. We had some reinforcement work done on the ground floor. And in this way, we made the building very safe (E.S.,42).

We had a technical analysis done due to earthquake risk. However, the report issued specified that the apartment did not entail an earthquake risk (Y.M.,65).

T4- Believing that there is no need to renew the house

A lot of people who chose to transform their building had made this decision to renovate their building. The ones who refuse to believe that their building does not need renovation, here are their comments:

We had some renovation done in the house. I don't need any further renovation (A.M.,80).

Our apartment is not that old, and we had done some minor alterations when we moved in. The interior of the house is quiet good actually (H.E.,38).

We had renovations done before moving in. I do not thinking like I should go with the transformation and renew my house (A.N.,39).

T5- Not daring to go through the transformation process with the concern that it will be too complicated The transformation process that has been going on in Bagdat Avenue for many years has resulted in negative experiences for some property owners. Here are the thoughts of the ones who do not dare to go through the transformation process because of the complications:

Yes, the apartment is quite old. Yet if we pull it down they will replace it with a 10-storey building. Right now everyone living in the apartments knows one another; we have order here. If we choose to knock it down and go for renewal, other people will start moving in. The contractor will sell the new flats to other people whom we don't know. We can never be sure who will move in. The contractors would not care about the identity of the person they sell to. They only care about the money they earn. We don't want anything to spoil our order (B.B.,53).

Since the municipality permitted to buildings up to 15-storey, buildings got into a competition of some kind. The contractor aims to reduce the floor area and build taller buildings. As houses with a sea view go for higher prices contractors come up with weird layout plans. At the same time they want the property owner to pay extra USD $100 \mathrm{~K}$ if he wants a house with a sea view. I don't want to become involved in a process like this (H.B.,53).

All our friends made agreements with the contractors to renew their apartments. And many suffered. The transformation process is not as easy as it is told (C.M.,64).

T5- The desire to maintain family inheritance

Some people consider their houses as more than a shelter for accommodation, and they feel it sets a connection between them and their past, their family. And these people do not wish to renew their building as they express with the following words:

The apartment's area was my mother's private estate in 1968 we hired an architect and built the apartment ourselves. We had done everything according to our desire. Now I am accustomed to each part of this house... I didn't meet with any of the contractors who wanted to change our house. I would not let them demolish this souvenir from my mother to make more money (F.K.,81).

This is a family apartment. I sent my children to Germany to study. And then they moved there. I frequently visit them. The reason I come here is to cherish the good old times. Being inside this house makes me remember my past, I feel good here. What good it is to me that they build a taller building to replace this house, it is only to the benefit of the contractor (B.K.,68).

T6- Reluctance to move into a smaller house as the result of the transformation process

After the transformation, the property owners are delivered smaller houses in $\mathrm{m} 2$ wise. There are so many people who do not wish to renew their houses for that specific reason:

The new house they give is smaller than the one we live in today. Frankly, I would not want that... (H.E.,38).

We recently renovated our house. I don't want my house to transform. Because in the end you get a smaller house. I would not be happy if the size of my house is reduced (Y.M.,65).

After the transformation process I would not be able to fit our existing furniture in the new house (C.M., 64).

\section{Discussion}

The field data is compared with the literature-based Sense of Belonging, Housing Satisfaction and Issue of Trust codes generated from the content analysis.

$\mathrm{C} 1$ - Sense of Belonging

The idea of generating economic advantage by reproducing urban spaces is the main reason behind the transformation process in Bagdat Avenue on plot-basis, which is true both for Turkey (Kuyucu \& Unsal, 2010; Balaban, 2012) and the whole world (Yhau \& Chan, 2008). Many stakeholders and contractors make transformation deals putting forward the earthquake risk (Berkmen \& Turgut, 2019), and it is seen that the primary 
expectation of both the property owners and contractors (Koramaz, 2018) is to produce more luxurious houses over urban spaces with high rent value and thereby to gain an economic advantage. However, this study sets forth that the ones who do not side with transformation have no economic expectations and that these people have developed a solid sense of belonging with their houses. In general elderly people who have been living the area for years stated in the interviews that they feel a sense of belonging both towards the neighborhood and their living space. In addition, having a family and a child in that residence is a crucial factor for developing belonging to the place. It has been determined that the sense of belonging of the middle age people, who have lived here for many years, to both their residences and the unique texture of the residential areas, has an essential share in resistance to transformation.

C2- Housing Satisfaction

The transformation process results in the renewal of buildings and increases in the value of the property, however as the volume increases, new people move to the area, which causes the current residents to move out (Kayasu \& Yetiskul, 2014). It is seen that the ones who do not want to undergo the transformation process are satisfied with their current neighbor relations, and they feel like part of the social structure that exists in which the fear will be lost as the result of the transformation.

This study reveals that the people who resist the transformation process have a high level of housing satisfaction. Their flats are generally well maintained. The ones who do not want to undergo transformation processes are generally satisfied with the condition of their current houses because the flats have recently been renovated. So the stakeholders do not feel the need for the destruction and the rebuilding process that will be accomplished as the result of transformation.

C32- Issue of Trust

Putting forth the expectations of the parties at the beginning of the entire construction process and managing the process is crucial in transformation projects with multiple stakeholders (Atkinson et al., 2006; Olander \& Ladin, 2005). Property owners living around Bagdat Avenue expect to have their buildings renewed, to get earthquakeproof houses, and to gain economic advantage. Much time during this process going on for many years, people witnessed how some contractors vanished in the middle of the work without completing the project or did not pay the rents on time as they have committed to pay, or abused the property owners by not delivering a high-quality construction as expected. Therefore the issue of not trusting the contractor and the process is a very critical factor for the people who do not support the transformation process.

\section{Conclusion}

It is seen that people who do not want their houses to transform are generally elderly and who have been living here for a very long time and thereby who developed a strong sense of belonging towards their houses and surrounding. The sense of belonging developed here is very closely related to both the social structure of the housing area and the physical properties of the houses. For that reason, people approach negatively to the increase in the number of people living in their apartment and change in the user's profile. Most property owners state that they already obtained a technical report, and thereby they claim their houses are earthquake-resistant and do not feel the need for transformation. Some property owners believe that the reinforcement works they had done have eliminated the earthquake risk, and there is no need to pull down their houses. All property owners interviewed expressed in general their satisfaction with their houses in both physical and social terms. Some of the transformation projects in the neighborhood resulted in the suffering of property owners because of contractors' failure to fulfill their commitments, and another code underlying in the motivation behind the decision of these property owners is the Issue of Trust.

Literature generally covers studies on buildings that have undergone transformation process and property owners that were part of these processes, whereas this study makes an original contribution by presenting the motivation of property owners who refuse the transformation process.

\section{References}

Abidin, N.Z., (2010). 'Investigating the awareness and application of sustainable construction concept by

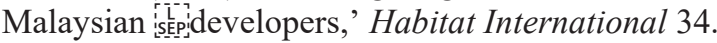

Angell, E., (2014). Assembling disaster: Earthquakes and urban politics in Istanbul. City, 18(6), 667-678.

Atkinson, R., Crawford, L., \& Ward, S., (2006). 'Fundamental uncertainties in projects and the scope of project management,' International Journal of Project Management, 24(8).

Balaban, O., (2012). 'The negative effects of construction boom on urban planning and environment in Turkey: Unraveling the role of the public sector,' Habitat International, 36(1).

Berkmen, N.H. \& Turgut, S., (2019). 'Kentsel Donusum Kiskacinda 'Bagdat Caddesi”,' Megaron, 14(S1).

Gruneberg, S. (2007). 'Performance-Based Contracting: An alternative approach to transacting in construction,' SLEP Constr. Manag. Econ. 25.

He, F., Wu, W., Zhuang, T. \& Yi, Y., (2019). 'Exploring the Diverse Expectations of Stakeholders in Industrial 
Land Redevelopment Projects in China: The Case of Shanghai,' Sustainability, 11(17).

Hin, L.L. \& Xin, L., (2011). 'Redevelopment of urban villages in Shenzhen, China-An analysis of power relations and iṣ̌p.

Kayasü, S. \& Yetişkul, E., (2014). 'Evolving Legal And Institutional Frameworks of Neoliberal Urban Policies In Turkey,' METU JFA, 31(2).

Koramaz, T. K., (2018). 'Housingisep' Renewal Sites and Spatial Features of Deterioration and Deprivation in Istanbul's Historic Peninsula,' Journal of Urban Planning and Development, 144(1).

Koskela, L. J. \& Ballard, G., (2006). 'Should project management be based on theories of economic or production?,' Building Research \& Information, 32 (2).

Kuyucu, T., \& Unsal, O., (2010). 'Urban transformation' as state-led property transfer: An analysis of two cases of urban renewal in Istanbul,' Urban Studies, 47(7).

Lovering, J., \& Turkmen, H., (2011). 'Bulldozer neo-liberalism in Istanbul: The state-led construction of property markets and the displacement of the urban poor,' International Planning Studies, 16(1).

Olander, S. and Ladin, A., (2005). 'Evaluation of stakeholder influence in the implementation of construction projects,' International Jornal of Project Management, 23.

Özkan Eren M. \& Özçevik, Ö., (2015). 'Institutionalization of Disaster Risk Discourse in Reproducing Urban Space in Istanbul,' ITU $A \mid Z, 12(1)$.

Williams, T. (2002)., Modelling Complex Projects, Chichester: John Wiley \& Sons.

Yhau, Y.S. \& Chan, H.L. (2008)., 'To rehabilitate or redevelop? A study of the decision criteria for urban 'išpiregeneration projects,' J. Place Manag. Dev. 1.

Zhuang, T., Qian, Q.K., Visscher, H.J., \& Elsinga, M., (2017). 'Stakeholders' Expectations in Urban Renewal Projects in China: A Key Step towards,' Sustainability, 9. 